\title{
Communicating health risks and crises: Exploring the experiences of journalists covering a proximate epidemic
}

\begin{abstract}
Media are an indispensable partner in health communication but, there is often concern about how the media cover health and science issues. These critiques tend to be based on analyses of news content that don't consider the production process of the content. Using a media sociology framework, the paper examines the news production process of the Ebola outbreak from the perspective of Ghanaian journalists. The study finds that routines influenced what the media produced. This study reiterates the call for public health to work closely with the media, and to provide translated health information in multilingual low literate societies.

Key words: Ebola, Ghana, news production, health news reporting, media sociology
\end{abstract}




\section{Communicating health risks and crises: Exploring the experiences of journalists covering a proximate epidemic}

The global community thought we had dealt with Ebola after the 2013-2016 epidemic was contained, but the ongoing Ebola outbreak in the Democratic Republic of Congo which has claimed almost 2000 lives in its 2000-day history (CDC, 2019) tells us that we have a long way to go. Addressing epidemics and health outbreak requires the active participation of the media since how journalists report issues can affect public perception of risks and influence behavior (Kitzinger \& Reilly, 1997; Roche \& Muskavitch, 2003). Yet studies on the content of health risk and crisis news show that the media tends to be inaccurate, contradictory, a poor reflection of disease incidence in real life, and sometimes incomplete (Bomlitz \& Brezis, 2008; Frost, Frank \& Maibach, 1997; Lemal, Custers, \& Van den Bulck, 2012; Molitor, 1993; Rubin \& Hendy, $1977)$.

Such content has been blamed on journalists' lack of training and specialization, educational levels, and challenges with understanding complex science and health information (e.g., Romano \& Thomas, 2017). The inherent assumption is that journalists have agency and autonomy and should take responsibility for problematic coverage. But without understanding the construction process of health news, our analysis of content lacks explanatory power about what we observe in the content and therefore the level at which changes and modifications can be made. In other words we need to consider the constraints and tensions within which journalists produce stories to better understand the content produced.

Studies have also analyzed the expectations of journalists in emergencies (Leask, Hooker \& King, 2010; Reynolds \& Seeger, 2005), news reporting processes that influence science and health journalism (Hodgetts, Chamberlain, Scammell, Karapu, \& Nikora 2008; Lowrey et al., 
2007), and how the media frame crises and disasters (Ewart \& McLean, 2015; Thomas, Kannaley et al., 2016). Most of these studies, however, have overlooked how the peculiar context of a health crisis influences the news content; fewer yet in developing countries.

The purpose of this study is to extend knowledge and scholarship on health risks and crises coverage by examining the production process of a proximate health crisis in a developing country. Guided by media sociology framework and using transcripts of semi-structured interviews with radio, newspaper, and television journalists in Ghana, I argue that the assumed agency and autonomy of the media should be viewed within the larger structural and systemic constraints within which media workers carry out their work. Although Ghana recorded no case of Ebola, it is an interesting context for study for the following reasons: (1) Ghana was pulled into the management of Ebola when it was made the host of the United Nations Mission on Emergency Ebola Response (UNMEER); (2) it was predicted to have the highest potential for Ebola virus dissemination through air travel; and (3) was named a priority country for preparedness strengthening (Bogoch et al., 2015).

This project contributes to practice and scholarship in the following ways: (1) The study contributes to the debate about problematic media reporting by moving the discussion away from content to unpacking the constraining and enabling structures in content production; (2) It builds the body of literature in a region of the world that is understudied, especially with respect to health crisis and risks (Amend \& Secko, 2012; Appiah et al., 2015); (3) It elucidates how the routines of coverage during the Ebola relate to content; (4) It brings the voices of African journalists to the debate surrounding health communication, voices which have been missing, (5) It contributes to the bigger picture of African science and health journalism specifically and African journalism broadly. 
Although HIV/AIDS in Africa research much research, Ebola, which is more virulent (fatality rate of 25\% - 90\%; WHO, 2016) has not received as much focus. By the end of 2015, the worst Ebola outbreak, which spread from Guinea into Liberia and Sierra Leone had claimed more than 11,000 lives (WHO, 2016). This research is thus relevant for the ongoing outbreak in D.R. Congo and for similar health crisis and infectious disease outbreaks that we may not anticipate.

\section{Media in Ghana}

Ghana has a thriving media environment, resulting from the liberalization of media in 1992 (Ansu-Kyeremeh \& Karikari, 1998). The media in Ghana are not only important sources of information, but also influential agenda setters, who influence opinion formation and social/behavior change (Leask et al., 2010; Thompson \& Yeboah, 2013). As of mid-2015, there were 354 operational FM radio stations out of the 452 authorized FM radio stations (www.nca.org.gh). This was made up of 326 commercial radio stations, 73 community radio stations, 31 public radio stations, and 17 campus radio stations. Thirty-four out of the 75 authorized television stations were on air (www.nca.org.gh). About 25 newspapers also operated (Yeboah-Banin \& Amoakohene, 2017). Although print media have a strong agenda setting function, they are limited in reach due to high illiteracy levels (Thompson \& Yeboah, 2013). Radio remains the most powerful medium in sub-Saharan Africa, and the most preferred and trusted medium for health information among Ghanaians (Bowen, 2010; GMSIP, 2009; Thompson \& Yeboah, 2013). Television is not as widespread as radio. The media were the main channels of risk communication for the Ministry of Health during the Ebola outbreak. 


\section{Literature review}

\section{Sociology of media/news production}

Though media sociology in the broad sense encompasses studying mass mediated communication, researchers have historically applied it strictly to the study of news media and called it news production studies (Brienza \& Rivers, 2016). Scholars have long admitted that what we know as "news" is socially constructed and determined by various forces within and outside the purview of news workers. Because news content has a "critical relationship" with how individuals view the world - in our case how audiences perceived and understood the Ebola epidemic - understanding the constructing process is central to understanding the qualities of news (Shoemaker \& Reese, 2014). News production analyses, then, address how news organizations and news workers produce news (Shudson, 1989).

Shoemaker and Reese (2014) proposed the hierarchy of influences model to facilitate multi-level analysis of influences on news content. They contend that each of these levels: individual, routine practices, media organizations, social institutions and social systems influence news content to different degrees. The individual, routine practices, and media organizations levels are internal to the media while the social institutions and social systems levels are external to the media. The linkage between and among the levels of influence is interactive and multidimensional (Shoemaker \& Reese, 2014). For instance, discussing issues of individual choice in news selection (individual level), necessarily involves considering the social context which influences the decisions the individual makes (social level) as well as the organizational culture which allows individual journalists to make autonomous decisions (organizational level).

Even though the hierarchy of influences model has been critiqued for lack of clear theoretical concepts, for its U.S. origins and conceptualization, and even Shoemaker and Reese 
(2014) have suggested that it is not a model in the true sense of the word, the model's utility and practicality coupled with its multimethod applicability make it appealing as a guiding framework for this study.

Shoemaker and Reese (2014) suggest focusing on one, two, or at most three levels of influence in any one study guided by the type of data, relevance to the issue under discussion, and practicality. Because the news is largely shaped by routines this study used routines as its level of analysis. The routines level of analysis involves considering the organization (organizational processes for efficient product delivery), audiences (knowledge or assumptions about their preferences) and sources (suppliers of information). Ross (2017) noted that, the values that drive routines are subject to alteration and may vary across national cultures and boundaries. The specific situation of a potential health crisis in a developing country may thus reveal certain routines that will not be evident in other situations.

\section{Health reporting}

Research has provided some breadth of knowledge about how journalists report on health. A National Cancer Institute sponsored study, that profiled American health and medical science journalists, found that journalists developed stories through a process that considered the credibility of the topic, topic relevance, and the importance of disseminating new information (Viswanath et al., 2008). Tanner, Friedman, and Zheng (2015) were interested in why local television health journalists cover the issues that they do. They found that news gathering practices in the health domain were different than general news reporting. Health journalists also saw their responsibility as going beyond providing credible information, to supporting education and health behavior change 
Relatedly, Amend and Secko (2012) undertook a meta-synthesis of qualitative research on health and science journalism in response to the scattered nature of existing qualitative studies. They found that the articles were mainly about North American journalists with a few from Europe and Australia and only one designated as international. Many of the studies focused on sourcing practices, story selection with others focusing on journalistic tools and routines, the role of the journalists, and audience. The authors recommend a multiplicity of locations and moments for qualitative health and science journalism studies to extend research in health journalism.

The story is however different with media that serve low resourced and minority contexts. For instance, Gearhart, Trumbly-Lamsam, and Adegbola (2018) surveyed journalists working in Native American communities about health news and found that although journalists viewed health as an important issue highly valued by their audience, health was not prioritized in practice. This low priority was attributed to leadership. Similarly, Appiah et al. (2015) in their survey of science and health journalism in Ghana found that many media organizations did not have science desks, and thus produced few science and health related stories. Again, barriers to science and health reporting included inadequate training, lack of access to scientific researchers, and a focus on non-science stories. What is missing, however, is how the journalists themselves perceive their knowledge and experience with health reporting.

If how journalists perceive themselves is critical to understanding how they carry out their responsibilities, then it is important to get journalists own expressions of how they perceive health journalism. It is appropriate then to start with a general understanding of Ghanaian journalists' knowledge and experience with health reporting because it provides a broad 
framework and context for situating the specific event of reporting about the Ebola outbreak. The study therefore builds on Appiah et al. (2015) and thus poses:

RQ1: What are journalists' knowledges and experiences with health reporting in Ghana?

\section{Routines in health risk and crisis reporting}

Journalists focus on different issues during risks and crises. Thomas, Friedman, et al. (2016) analyzed how traditional and social media communicated health risks, about the 2014 West Virginia water crisis and found that, health risk information was not high in either medium. Hooker, King, and Leask's (2012) study of Australian journalists' coverage processes during the potential pandemic of avian influenza found that, "catastrophic potential, cultural and geographical proximity, unfamiliarity and uncertainty" (p. 224) influenced coverage. Again, they found that journalists focused on pharmaceutical and technological responses to the outbreak rather than the reactions of community members or even government preparedness to handle a potential pandemic. Journalists were also torn between reporting what the public was interested in and reporting on the crisis mitigation efforts of health officials. Leask, Hooker, and King (2010) in their study of Australian influenza and pandemic planning found that time, resource, and technical expertise constraints challenged journalists' ability to produce high quality stories. Furthermore, journalists' gatekeeping role and frameworks of what constitutes a good story influenced story selection. Journalists both actively and passively acquired sources for stories.

Shih, Wijaya, and Brossard, (2008) examined how the New York Times had covered three health hazards (avian flu, West Nile virus and mad cow disease) over a 10-year period and found that journalistic norms and routines such as proximity, location, and impact influenced placement and the theme of stories. Shih, Brossard, and Wijaya, (2011) studied content of news 
coverage about the avian flu and West Nile virus in the U.S. and found that journalists, relied on bureaucratic sources to the detriment of those affected. They argue that news practices during health risks and crisis may not differ from coverage of other health issues.

In a textual analysis of how the media covered the polio outbreak and its ensuing campaigns in Indonesia, Romano and Moran (2018) found that the stories were sensationalized, lacked contextualization and fact checking. They attributed some of these challenges to contextual factors such as low levels of education, professionalism, financial insecurity, and ethics. The researchers also faulted journalists for publishing stories that lacked news worthiness.

These studies give us a glimpse of how risks and crises are covered by the media. Clearly the type of risk or crisis concerned, and the context within which it occurs influence the content produced. What remains, is the perspective of journalists on the production processes that influences their content during such situations. The next two research questions therefore assessed Ghanaian journalists' conception of their production processes during the Ebola outbreak

RQ2: What were Ghanaian journalists' production processes (idea generation, story selection, story angle) on news about the Ebola outbreak?

RQ3: What kinds of information did journalists focus on and what were their sourcing practices?

\section{Impacts of health risk reporting}

Journalist have been both blamed and defended in their coverage of health risks and crises. On the one hand, the media have been praised for covering health risk and crises effectively. Duncan (2009) found in a study of European print media that in the initial days of the swine flu epidemic, print media in Europe provided factual and non alarmist coverage of the 
outbreak. He attributes this finding to the media's access to accurate and credible information. Similarly, Hilton and Hunt (2011) found that the U.K. print media coverage of the 2009-2010 swine flu was measured, factual, not sensationalist and did not over represent the issue. In the case of the 2001 anthrax scare, Shapiro, Thomas, and Rowan (2007), blamed government sources and public health officials and researchers for information scarcity, leading journalists to rely on "second tier and even bogus experts" (para. 14).

On the other hand and predominantly, the media have been blamed in their coverage of health risks. Romano and Moran (2017) found that problems with reporting, including sensationalism, not checking facts, and burying the lead behind dramatic headlines, led to reduced polio vaccine uptake in some communities in Indonesia. Vasterman, Yzermans, and Dirkzwager (2005) showed a correlation between media hype and increased health problems after a disaster. They found that when the media hyped a particular perspective of a health implication after a disaster, audience members tended to adopt these explanations and attribute their health problems to the disaster. Kittler et al. (2004) faulted the media for invalidated, variable, and shallow coverage of the 2001 anthrax scare.

These studies demonstrate that how journalists report health issues influences the way audiences interprete and act on those issues. However, it is unclear how journalists perceive the impact of their reporting on audiences. The final research question asks:

RQ4: What do journalists think were the impacts of their reporting on audiences?

\section{Method}

I used face-to-face semi-structured in-depth interview method with key informants and respondents to gather data, because it allows flexibility and is effective for gathering data about 
experiences and perspectives, and inquiring about the past (Lindloff \& Taylor, 2011). The indepth interview method was situated in social constructionism - the belief that people make and maintain meaning based on interactions with others and one's social and cultural context (LeedsHurwitz, 2009). It also allowed the voices of African journalists which had been missing in such debates to be brought to the table. The study site was Accra because it is the capital of Ghana and hosts most media organizations in the country. The author is Ghanaian, completed her postgraduate education in communication studies in Ghana and has intimate knowledge about the media in Ghana. The author was thus able to gain access and build trust with the respondents. The researchers' institutional review board approved the study.

\section{Sampling and Recruitment}

This study focused on individuals who work with legacy media organizations (newspaper, television, and radio) as news gatherers, anchors, presenters, producers, or editors (news workers). Although I focused on legacy media, many respondents publish in more than one format due to convergence and the digital platforms that all of the organizations own. A list of local newspapers, television, and radio stations authorized to operate in Accra during the peak of the outbreak (June -December 2014) was acquired. There were 44 local radio stations with 27 operational FM stations (excluding community and campus radio stations) serving the greater Accra region. Nine out of the 14 approved local free to air television stations were also operational (www.nca.org.gh). Initial phone calls were made to these media to explain the research and to identify potential participants. I also purposively sampled and contacted reporters/editors in legacy media, who had published articles on the Ebola crisis, and through snowballing, they recommended other news workers to participate. I sent invitations to all the contacts (25 in all). Due to the use of qualitative sampling, the findings cannot be generalized to 
the entire media in Ghana. Follow-up calls and invitations were done after two weeks to schedule interviews. All the interviews were conducted in English. Interviewees were both informants and respondents (Lindloff \& Taylor, 2011). As respondents, they provided responses to the questions, while as informants, they instructed me on their settings, culture, and actions based on their experiences and knowledge (Gabor, 2017; Morse, 1991).

Five respondents worked for public media and the remaining respondents worked for private media organizations. There were seven journalists/reporters, five senior reporters or senior journalists and six producers/editors ${ }^{1}$. The minimum educational level of a respondent was a higher national diploma (HND; equivalent to an associate degree), and the highest was a master's degree. Table 2 shows the demographic characteristics of respondents. All had been journalists for at least four years.

Interviews were conducted in-person during the field work period of August-September 2015 and lasted between 45-120 minutes. They were held at venues that respondents chose and were comfortable with, including journalists' offices and a restaurant. Respondents were assured of confidentiality for the information provided. Each respondent provided written consent to participate in the study and was given a copy of the signed consent form. Interviews were digitally recorded.

After 18 interviews, all the recommendations were of participants who had already been interviewed, and no new information was received confirming data saturation. Although 18 interviews may seem small, guided by Morse (2000) criteria for qualitative sample sizes, this size is adequate for the issues interrogated and consistent with health reporting studies elsewhere

\footnotetext{
1 The labels refers to positions that interviewees hold in their organizations. Although the term "senior journalists" is sometimes used in Ghana to signify a journalist's experience level, its use here is based on organization position designation.
} 
(Hodgetts et al., 2008; Hooker, King \& Leask, 2012; Leask, Hooker \& King, 2010; Tanner, Friedman, \& Zheng, 2015). First, the scope of the study was specific to journalists who had published stories on Ebola and who could speak as respondents. Second, the clear nature of the topic allowed interviewees to share their experiences as informants. Interviewees also provided shadow data by commenting on how other journalists had reported the epidemic (Morse 2000).

\section{Interview Guide}

A semi-structured interview guide consisting of four main questions that allowed for open-ended responses was used in gathering data. The first question focused on the journalist's knowledge about and experience with health reporting generally in Ghana. The second and third questions focused on influences, practices, and motivations of journalists when reporting on Ebola (e.g., idea development, story selection, angling, sourcing, personal emotions, and experience). The fourth question addressed the perceived impact of the coverage on Ghanaians. Demographic questions including journalists' education levels and years of experience were also obtained. Probes were used to elicit further information and to explore concepts that came up during the interviews. The instrument was pilot tested with other journalists and revised prior to data gathering.

\section{Coding and Analysis}

The interviews were transcribed verbatim and I acquainted myself with the data in the process. I undertook thematic analysis in the tradition of the grounded theory approach (Sandelowski, 2000). Data analysis proceeded in three iterative steps. First, I generated initial open codes (etic codes) that closely related to the words used by the interviewees. Initial codes 
were combined and labeled into emic codes or categories (generated by the researcher) guided by the research questions (Kottak, 2006). Finally, I abstracted themes by identifying patterns and drawing out the relationships among the categories, relating them to the research questions and the theoretical framework (Noble \& Mitchell, 2016). Table 1(adapted from Ofori-Parku, 2018) outlines how I understood and examined the data from an interpretative perspective. Four themes emerged from the study. These are: underdeveloped health reporting; editorial constraints, journalism of conversations, or journalism of advocacy/mediation; reactionary sourcing, alternative sourcing, or flushing out; and causing or reflecting fear.

\section{Results}

\section{Underdeveloped health reporting}

To return to the respondents' background presented earlier, journalists in Ghana seems to be carving out things out in an eclectic manner from diverse backgrounds based on the multiple ways workers end up in the newsroom. Of the 18 respondents, about half had journalism training at either the HND, bachelor's or post graduate degree. The rest came into journalism from various backgrounds including agriculture, marketing, biology, business management, and architecture. This background helps to contextualize the findings.

Research question one asked about journalists' knowledge and experience with health reporting in Ghana. A routine found in the current study is low prominence of health reporting in Ghana. Unlike studies in other countries (e.g., Tanner, Friedman, \& Zheng, 2015), but consistent those from low resourced contexts (Appiah et al., 2015; Romano \& Moran, 2017), health reporting is not a specialized area of reporting in Ghana. Interviewees stressed the importance of 
health reporting but indicated that health is not a priority in many media houses, unless something out of the ordinary happened.

When it comes to newsroom journalism itself, you don't find a lot of the health stories just being done... When the red flags are raised, and a warning needs to go out to the public, then it happens ... it usually centers on something sensational, but we are doing our best. (Journalist, Radio/Television)

Ebola received attention because it had the news values of dread, novelty, catastrophic potential, and proximity (Hooker, King, \& Leask, 2012). Only a few media organizations had health desks, but the stories from the health desk were published as magazine programs (broadcast) or features in weekend papers. Such routinization creates a convention where general health issues are relegated to human interest stories, magazine programs, or to soft news and weekend newspapers. Newspaper journalists explained that health is combined with gender and children's issues in many newsrooms. Respondents use of "we are doing our best" regarding health reporting in this study may be a defensive mechanism which serves to minimize the lack of focus on health while giving journalists agency and recognition for their efforts.

Other reasons suggested for the lack of focus on health issues were lack of specialization in health reporting, and inadequate resources.

We don't have in-depth knowledge about health issues because it is rare to find a journalist who has specialized in that area. So, we are unable to bring out the right issues and get them addressed. (Journalist, Radio)

If your stories show that you are competent in handling the subject related to a particular field, the news editor will always assign you there. In journalism, you must demonstrate. (section editor, newspaper)

As the editor explained in the quotation above, journalists start off as generalists and are assigned to a beat based on editorial considerations and types of stories written in the past. The unpredictability of news events may lead editors to encourage a system where all journalists are generalists instead of encouraging specialization (Lowrey et al., 2007). Such routinization 
presents a challenge during crises because, journalists may not understand science and the uncertainties associated with scientific knowledge and may not be able to accurately interpret information (Holmes, Henrich, Hancook, \& Lestou, 2009).

While news workers in Gearheart et al. (2018) study attributed low priority of health reporting to leadership, some news workers in the current study attributed it to perceived audience interest in political issues. As one radio journalist said, "you know Ghanaians like politics, and we need to respond to our audience." Thompson and Yeboah made a similar observation of a "seeming listener disinterest in health-related stories" in Ghana (2013, p. 383).

\section{Editorial constraints, journalism of conversations, or journalism of advocacy/mediation}

The second research question (RQ2) asked about journalists' news production processes during the Ebola outbreak. Similar to other studies (Tanner, Friedman, \& Zheng, 2015) journalists viewed themselves as fulfilling the normative roles of educating and informing audiences about the Ebola outbreak, but the approaches used differed. When reporting about the Ebola epidemic, some journalists were influenced by organizational or editorial constraints.

State media journalists, for instance, were constrained by their state affiliation in what they could cover. As one senior television journalist captured it, "in public service, there is only so much that you can do and cover. In actual fact, we are cash trapped and are stifled in what we can cover and what we can’t; you know your paymaster,” suggesting governmental influence on news content. While some private media editors or editorial teams decided on the stories, other journalists had much more autonomy. The following examples illustrate these sentiments.

When I came back from an assignment, I discussed with my editor that I wanted to do a feature on it and he agreed. (Journalist, Radio) 
I did stories on the 'ban' on hugging and stories on churches. The angle was determined by my news editor. If you did a story that did not correspond to our editorial style, it would not be aired because we had had a lot of court cases. (Senior journalist, Radio)

Other journalists engaged in a journalism of conversations, where "journalists see themselves less as 'detached observers' of society, but rather as a part of society" (Hodgetts et al., 2008, p. 46). Here, respondents' motivations for picking the angles, were based on their own experiences and observations about how people behave in society. These included everyday habits, social, cultural, orientations/actions, and their knowledge about Ghanaian practices.

People engage in involuntary acts such as picking their nose, rubbing their eyes without being conscious of those things, and that is how the disease spreads. I chose this angle because of how contagious the disease is, and how one can easily get infected even without realizing it. (Senior Journalist, Radio)

I decided to focus on religious reactions. Everybody was doing the hospitals and bush meat and bats, but we are a very religious society. You find people in church and the mosque every day. It was the Ghanaian lifestyle. When Moslems meet, they virtually share a buta [kettle for ablution]. Most of our churches do deliverance [cleansing individuals of evil spirits] and people fall; most of the charismatic churches dance a lot and people sweat. So, I wanted to focus on the religious. (Senior Journalist, Radio/Television)

The possibility of infection through familial engagement and relations also motivated story ideas.

A senior editor's concern about possible infection through her children led to a story:

I have children in school, and I was always worried that they might bring the disease home. You don't know what they do at school. So, I did a story about school children and school preparedness.

Journalists, thus, explored the crisis as representatives of the society in which they were located by using their personal experiences and contextual knowledge to guide story selection and angles.

An important advocacy and mediation role of the media is between lay audiences and authorities. Some media engaged in journalism of advocacy or mediation. Local language media, for instance, provided information translation function during the outbreak. As a radio journalist 
explained, "Ebola and everything about it was in English, so we had to break it down into the local language to help them understand." In addition, local language media viewed their role as educating and providing a platform for the "ordinary citizen" and low literate to air their opinions and concerns. The local language media's use of vox pop, for instance, afforded minority voices a platform that they hitherto would not get.

I went to the market or trotro stations [public transportation terminals] and asked people what they know about the disease, questions they have, and what they want government to do," a local language radio journalist explained.

They however acknowledged that they struggled to find appropriate translations for scientific terminology (e.g. Akan translation of a virus or hemorrhage) to explain the disease and its symptoms. This advocacy and mediating role might be fraught with challenges (inaccurate translation) which require further examination.

Journalism of advocacy and mediation was also evident in the private media which echoed a sense of mistrust for government. Such respondents viewed themselves as advocating for the needs of their audience during a time of immense concern, and holding government accountable to the people. An editor in a private radio station, explained that:

We were being skeptical of government and probing of its utterances on Ebola prevention. If they can't control cholera, how much more Ebola? The isolations centers are still being built, how? There is a lot of mistrust between media and government and authority generally.

Such skepticism emanates from the media's role as watchdogs of government institutions. This tension was also evident in Lowrey et al.'s (2007) study, which found that journalists seek to inform the public about health risks but may also become suspicious of government health agencies in their role as watchdogs on government institutions. 


\section{Reactionary sourcing, alternative sourcing, or flushing out}

The third research question (RQ3) ascertained news workers information needs and sources during the outbreak. While some sought information about causes, symptoms, treatment of Ebola as well as Government's strategies to prepare the country for possible infections, others focused on what government (and its ministries) were doing, government delegations, and the simulation sessions held. Respondents' main sources of information were official sources including government and scientists/ health experts but for different purposes. Respondents from public sector were the mouthpiece of government and thus sought information about the activities the government was undertaking, while respondents from private media sought information about the what government was supposed to do as the quotation above showed. Interviewees especially from public service thus engaged in reactionary sourcing by depending on official sources (Hodgetts et al., 2008). A senior public media journalist in radio, for instance, said "because it was something new, the Ministry of Health was always willing to give out information. The information was coming easily. They gave us information about delegations that were coming in and going." This view was contradicted by a private media senior journalist who said, "It was so difficult to get information from government communicators and ministers and even from Noguchi [a biomedical research institute) ...."

Under normal circumstances, Ghanaian health journalists rely on official human sources for information (Appiah et al., 2015). But in information scarcity in a potential epidemic, journalists to find alternative sources of information with varying credibility levels (Shapiro, Thomas, \& Rowan, 2007). In the current study, international media, and social media became sources of information about Ebola. As one senior journalist shared, "we depended on what we found on the internet ... mainly on reportage from international media such as BBC and CNN." 
Dependence on international media (rather than media from affected countries) made journalists fall victim to one-way flow of information reminiscent of cultural imperialism and shows the continued influence of international media on local media content. Another respondent recounted, "because of competition and their bid to try to be the first to report, some journalists were taking their information from social media, leading to discrepancies in the reportage and the figures given out." Reliance on such sources for information without verification, may have resulted in inaccurate information being disseminated.

A final strategy adopted by broadcast media in information scarcity was the "flushingout" strategy. This strategy involved putting out all the information the media had gathered without necessarily verifying the accuracy or credibility and then calling officials on air to clarify the issue or correct inaccuracy.

To get information from a member of government or authority, you have to trick the truth out of them. Because they won't give it to you. Well, maybe because there is no freedom of information act, they won't give you the information (Senior Journalist, radio)

At that time, we didn't have the luxury of sifting the information. Make sure they know everything they need to know about Ebola and then the rest depends on them. (Journalist, Television)

At the time of the outbreak, there was no Right to Information law which could be used to access information ${ }^{2}$. Flushing out was thus a way of forcing experts and authorities to provide the required information and clarification. However, with the non-captive audience of radio and television, this strategy could mislead audiences, who may not pay attention to the entire news item leaving them with unverified information. Journalists could therefore in one breadth be both educating and misinforming audiences.

\footnotetext{
${ }^{2}$ The Right to information Act was passed on March 12019 (http://ghana.gov.gh/index.php/mediacenter/news/5641-president-gives-accent-to-law-on-right-to-information)
} 


\section{Causing or reflecting fear}

The last research question asked news workers about their perceptions of the impacts of their reporting on their audiences because in a media dependent society such as Ghana, audiences tend to adopt the explanations provided by the media. Although all respondents felt that they increased knowledge about Ebola through their reporting, their views diverged on the negative impacts. Some respondents acknowledged a general sense of 'fear and panic' among Ghanaians during the period and attributed it to how journalists sensationalized their reporting:

From the beginning, the whole thing was about creating a huge fear and panic; the whole disease came with a quick death; the disease came with pictures. In Ghana, if you want to attract people's attention, then you need to look at the fatality. (Television Editor)

It was how we reported it that led to the fear and panic, especially our local language [media .... It was all kind of warning, alarmist. (Senior Journalist, Radio)

A possible cause of the panic was the media's use of words, descriptions, translations, and emotions that startle audiences, a form of media hype (Romano \& Moran, 2017). Although hyping (Vasterman, Yzermans, \& Dirkzwager 2005) may sustain the interest of the citizens in the issue, but it may also lead to unwarranted anxiety and panic. For others, concerns about audience fear and panic may have been a result of the unintentional need to provide information and explanation to audiences:

It was better to tell the people about what the situation was. We just did what was expected of us. I don't think we increased panic. It is a human institution and there could have been one or two reports that exaggerated the situation, but that I think was negligible. (Reporter, Newspaper)

There is the possibility that some sensationalism happened. Because in our local language, you don't get direct translations from English. Sometimes you have to put two, three, or four words together to get the meaning of one English word. The presenters bid to explain technical issues to the low literate populace may have made others term it as sensationalism. (Journalist, local language radio) 
Others argued otherwise, suggesting that media only reflected the views of society. If there was 'fear and panic' the media only mirrored what was already in existence:

My belief has always been that what we [journalists] do is reechoing what is happening in the society. If there is a lot of fear around you, you represent it on the airwaves so that those who are in charge will take steps to assure these people that 'this is what we have done to deal with it, and therefore there is no cause to fear.' (Editor, Radio/Television)

\section{Discussion and conclusion}

I sought to unpack the constraining and enabling structures and processes in news production during a proximate health crisis (Ebola) in Ghana. In line with what other studies have found among vulnerable and low-resourced communities (e.g., Gearhart et al., 2018) the current study showed underdeveloped health reporting due to certain routines and practices within journalism practice in Ghana. First, perceptions or assumptions about the audience influence journalist in making decisions about stories (Hinnant, Len-Rios, \& Oh, 2011). The perception that audiences prefer politics seems to be guiding journalists to focus more on political issues. This was surprising given that half of the winners of the prestigious Journalist of the Year award in the last 10 years have won based on health-related issues they reported. Perceived audience disinterest in health news could be a result of the cultivation hypothesis. With the liberalization of the airwaves in the 1990s, news workers focused on their watchdog role of the young democracy by reporting on the (in)actions of government (Thompson, 2019). The media's focus on politics may have cultivated in the audience a priority for politics in news. Further investigations will help clarify this issue because there is currently no study about audience preferences for news in Ghana.

Organizational processes also influence low health reporting. With the unpredictability of news, media organizations lean towards having generalist journalist than specialists (Lowrey et 
al., 2007). Furthermore, there seems to be direct organizational influence on media content with some media owners or editors determining what gets published. Such processes may lead to less focus on health in news.

The third routine that results in low health reporting practices seems to emanate from journalism culture and views about news values. Health issues need to border on the extreme to merit coverage. Added to this is journalists defense mechanism of "doing our best." Such attitudes may prevent journalists from recognizing the low priority given to health and therefore the need to address health in the news.

In the context of reporting on the Ebola epidemic, while some journalists were constrained by organizational or editorial influences and only reported what the media organization approved, other journalists engaged in a journalism of conversations, in which journalists explored the crisis as representatives of their society and culture.

Others engaged in a journalism of advocacy or mediation by keeping a keen eye on government and health agencies (non) response to the crisis or by affording minority voices the platform to share their concerns and translating information into local language for audiences. This advocacy and mediating role might be fraught with challenges (e.g., inaccurate translation), which requires further examination.

Thirdly, in a health crisis, during information scarcity, journalists may adopt different sourcing strategies (Shapiro, Thomas, \& Rowan, 2007). Three main strategies were identified in the study. They are reactionary sourcing where journalists responded to the agenda of official and expert sources, alternative sourcing where journalists depended on the internet or other known international media for news information, and the flushing out strategy where journalist, 
usually in broadcast media, published all information gathered without necessarily verifying and then calling officials on air to clarify issues.

Each of these sourcing strategies has inherent challenges for the type of content that is produced and the credibility of the information. Dependence on official sources has the potential of providing accurate information, but it can also lead to promoting the agenda of elite groups and shut out alternative voices and perspectives. Alternative sourcing is a good practice because it allows for varying perspectives. But it has the potential to propagate falsehood and misinformation especially when the credibility of online sources cannot be ascertained or may lead to continued dependence on foreign media. Flushing out can force official sources to provide information, but it can also lead to misinformation as explained earlier. Journalistic routines for cross checking, verification, and multiplicity of sources must be upheld especially during times of anxiety. It is unclear how these strategies impacted audiences but one can speculate that they played a part in the "fear and panic" that respondents expressed.

Finally, in an unfamiliar epidemic, the media may play a part in the existing fear and panic (Gearhart et al., 2018). The issue then might be how to help journalists see the two-edged sword of the approaches and strategies they adopted during the Ebola outbreak.

This study is not without its limitations. The use of interviews and recall has inherent gaps that need to be acknowledged, but the use of shadow data and the focus on a distinct group of journalists lessens this problem. Second, this study focused on media in the capital of Ghana. Further research with media in the border towns may uncover nuances not evident in this study. A study with audiences will establish whether the perceptions the media have about their audience interests hold true. 
Based on the findings and discussion, some recommendations are in order.

Conscientization (Freire, 1973) might be a way for news workers to work to address short comings and challenges in the approaches and strategies used during the Ebola outbreak. Freire conceived of conscientization as a way of people achieving a deeper awareness of their sociocultural reality and taking action to address the shortcoming. Conscientization here would involve journalist and editor (from similar of different media) developing a critical consciousness about how the media organization operates, its routines, reflecting on the impacts and implications, and taking action to address them by devising strategies for speaking up and pushing for changes from systemic and structural power holders. I do not seek to bury systemic influences that result in problematic coverage, but rather to show that various levels of influence affect media content and each level requires a different approach.

Media organizations should consider journalists who covered the outbreak as resources who can suggest how such crisis should covered. In that vein, media houses in Ghana could hold joint simulation sessions where those who covered the outbreak share ideas about how journalists might cover such issues or illuminate the shortcomings of approaches adopted. Such collaboration should involve local and international nonprofits in the sector as well as health experts in order to build connections and share ideas.

In crisis situations, public health experts and communicators should prepare information in a timely and usable manner to satisfy journalists' need for full, accurate, and clear information (Hooker, King, \& Leask, 2012). But journalists also need to watch out for the possibility of becoming dependent on such information subsidies. Public health experts in multilingual societies need to prepare information in local languages, to ensure standardization in translation and interpretation by local language media because local language journalists play a vital role in 
in public health communication by meeting the needs of various audience segments and breaking the elite-centered focus of journalism.

Journalism education in Ghana should give some focus to translation and contextualization in journalism training to adequately prepare journalists for the market. As more journalists are learning on the job, it behooves media houses to provide resources for reporting on a variety of issues, while working with journalists to identify areas of specialization, especially health.

Finally, there is a need for media and public health professionals to understand the unique but important role that each party plays, to work together beyond the rhetoric of the need to work together (Holmes, Henrich, Hancook, \& Lestou, 2009) to build and strengthen the journalistpublic health relationship (Holmes, Henrich, Hancook, \& Lestou, 2009; Lubens, 2014). This is especially important in public health risks and crises. 


\section{References}

Amend E. \& Secko D., M. (2012). In the face of critique: A meta-synthesis of the experiences of journalists covering health and science. Science Communication, 34 (2), 241-282.

Ansu-Kyeremeh, K., \& Karikari, K. (1998). Ghanaian media overview, practitioners and institutions. School of communication studies printing press, Accra.

Appiah, B., Gastel, B., Burdine, J. N., \& Russell, L. H. (2015). Science reporting in Accra, Ghana: Sources, barriers and motivational factors. Public Understanding of Science, 24(1), 23-37.

Bomlitz, L. J., \& Brezis, M. (2008). Misrepresentation of health risks by mass media. Journal of Public Health, 30(2), 202-204.

Bogoch, I. I., Creatore, M. I., Cetron, M...Khan, K. (2015). Assessment of the potential for international dissemination of Ebola virus via commercial air travel during the 2014 West African outbreak. Lancet, 385(9962), 29-35 21.

Brienza, C., \& Revers, M. (2016). The field of American media sociology: Origins, resurrection, and consolidation. Sociology Compass, 10 (7), 539-552.

Center for Disease Control (2019, August 29). Ebola outbreak in eastern Democratic Republic of Congo reaches 3,000 cases and 2,000 deaths. [Press release]. Retrieved from https://www.cdc.gov/media/releases/2019/s0829-ebola-cases.html

Duncan, B. (2009). How the media reported the first days of the pandemic (H1N1) 2009: Results of EU-wide media analysis. Eurosurveillance, 14(30), 19286.

Ewart, J., \& McLean, H. (2015). Ducking for cover in the "blame game": News framing of the findings of two reports into the 2010-11 Queensland floods. Disasters, 39, 166-184. doi:10.1111/disa.12093 
Freire, P. (1973). Education for critical consciousness. New York, NY: Continuum.

Frost, K., Frank, E. \& Maibach, E. (1997). Relative risk in the news media: A quantification of misrepresentation. American Journal of Public health. 87(5), 842-844.

Gabor, E. (2017). Informant Interviews. In M. Allen (Ed.), The sage encyclopedia of communication research methods, (Vol.1, pp. 700-702). Thousand, CA: Sage.

Gearhart S., Trumbly-Lamsam T., \& Adegbola O. (2018) Why Isn't Health a Priority?, Journalism Practice, 12(9), 1183-1200.

Ghana Media Standard Improvement Programme (GMSIP). (2009). Journalism in practice: A study of newspaper and radio content in Ghana. Unpublished research report submitted to the Media Foundation for West Africa (MFWA).

Hilton, S., \& Hunt, K. (2011). UK newspapers' representations of the 2009-10 outbreak of swine flu: one health scare not over-hyped by the media? Journal of Epidemiology \& Community Health, 65(10), 941-946.

Hinnant, A., Len-Rios, M. E., Oh, H. (2011). Are health journalists' practices tied to their perceptions of audience? An attribution and expectancy-value approach. Health Communication, 27(7), 234-243.

Holmes, J. B., Henrich, N., Hancock, S., \& Lestou, V. (2009). Communicating with the public during health crises: Experts' experiences and opinions. Journal of Risk Research, 12(6), 793-807.

Hooker, C., King, C., \& Leask, J. (2012). Journalists' views about reporting avian influenza and a potential pandemic: a qualitative study. Influenza and other respiratory viruses, 6(3), 224-229.

Hodgetts, D., Chamberlain, K., Scammell, M., Karapu, R., \& Nikora, L. W. (2008). Constructing 
health news: possibilities for a civic-oriented journalism. Health: An Interdisciplinary Journal, 12(1), 43-66. doi.org/10.1177/1363459307083697

Kittler, A. F., Hobbs, J., Volk, L. A., Kreps, G. L., \& Bates, D. W. (2004). The Internet as a vehicle to communicate health information during a public health emergency: A survey analysis involving the anthrax scare of 2001. Journal of Medical Internet Research, 6(1)e8.

Kitzinger, J., \& Reilly, J. (1997). The rise and fall of risk reporting: Media coverage of human genetics research, 'False memory syndrome' and 'Mad cow disease'. European Journal of Communication, 12(3), 319-350. doi:10.1177/0267323197012003002

Kottak, C. (2006) Mirror for Humanity. New York, NY: McGraw-Hill.

Leask, J., Hooker, C., \& King, C. (2010). Media coverage of health issues and how to work more effectively with journalists: A qualitative study. BMC Public Health, 10(1), 535.

Leeds-Hurwitz, W. (2009). Social construction of reality. In S. Littlejohn, \& K. Foss (Eds.), Encyclopedia of communication theory. (pp. 891). Thousand Oaks, CA: Sage.

Lemal, M., Custers, K \& Van den Bulck, J. (2013). The portrayal of health problems in entertainment television: Implications for risk perception and health promotion. in J. Merrick (Series Ed.), Health and Human Development: Public health Year Book (pp. 8192). New York, N.Y: Nova Science Publishers

Lindlof, T. \& Taylor, B. C. (2011). Qualitative communication research methods $\left(3^{\text {rd }}\right.$ ed.). Thousand Oaks, CA: Sage.

Lowrey, M., Evans, W., Gower, K. K., Robinson, J. A., Ginter, P. M., McCormick, L. C., \& Abdolrasulnia, M. (2007). Effective media communication of disasters: Pressing problems and recommendations. BMC Public Health, 7(1). doi:10.1186/1471-2458-7-97 
Lubens, P. (2015). Journalists and public health professionals: Challenges of a symbiotic relationship. Disaster Medicine and Public Health Preparedness, 9(1), 59-63.

Machin, D., \& Niblock, S. (2006). News production theory and practice. New York, NY: Routledge

Morse, J. M. (1991). Editorial: Subjects, respondents, informants, and participants? Qualitative Health Research, 1 (4), 403-406.

Noble, H., \& Mitchell, G. (2016). What is grounded theory? Evidence-Based Nursing, 19, 34-35.

Reynolds, B., \& W Seeger, M. (2005). Crisis and emergency risk communication as an integrative model. Journal of Health Communication: International Perspectives, 10(1), 43-55. doi:10.1080/10810730590904571

Romano, A., \& Moran, T. (2017). News media reporting of health crises in developing nations: Lessons from Indonesia's polio outbreak. Australian Journalism Review, 39 (2), 7989.

Roche, J. P., \& Muskavitch, M. A. (2003). Limited precision in print media communication of West Nile Virus risks. Science Communication, 24(3), 353-365.

Ross, A. A. (2017). "If nobody Gives a Shit, is it Really News?” Changing standards of news production in a learning newsroom. Digital Journalism, 5(1), 82-99.

Rubin, D. M., \& Hendy, V. (1977). Swine influenza and the news media. Annals of Internal Medicine, 87(6), 769-774.

Sandelowski, M. (2000) Focus on research methods-whatever happened to qualitative description? Research in Nursing \& Health 23(4), 334-340.

Schudson, M. (1989). The sociology of news production. Media, Culture \& Society, 11, 263-282.

Shapiro, B., Thomas, P. \& Rowan, F. (2007). Interaction of journalists and sources.

Nieman Reports. Retrieved from Nieman Foundation for Journalism at Harvard website. 
http://www.nieman.harvard.edu/reportsitem.aspx?id5100263.

Shih, T. J., Wijaya, R., \& Brossard, D. (2008). Media coverage of public health epidemics: Linking framing and issue attention cycle toward an integrated theory of print news coverage of epidemics. Mass Communication \& Society, 11(2), 141-160.

Shih, T., Brossard, D., \& Wijaya, R. (2011). News coverage of public health issues: The role of news sources and the processes of news construction. International Public Health Journal, 3(1), 87-97.

Shoemaker, P. J., \& Reese, S. D. (2013). Mediating the message in the 21 st century: A media sociology perspective, (3rd ed). New York, N.Y: Routledge.

Tanner, A. H., Friedman, D. B., \& Zheng, Y. (2015). Influences on the construction of health news: the reporting practices of local television news health journalists. Journal of Broadcasting \& Electronic Media, 59(2), 359-376.

Thomas, T. L., Friedman, D. B., Brandt, H. M., Spencer, S. M., \& Tanner, A. (2016). Uncharted Waters: Communicating Health Risks During the 2014 West Virginia Water Crisis. Journal of Health Communication, 21(9), 1062-1070.

Thomas, T. L., Kannaley, K., Friedman, D. B., Tanner, A. H., Brandt, H. M., \& Spencer, S. M. (2016). Media Coverage of the 2014 West Virginia Elk River Chemical Spill: A MixedMethods Study Examining News Coverage of a Public Health Disaster. Science Communication, 38(5), 574-600.

Thompson E. E. (2019). Ghana. In D. Merskin (ed.), The Sage International Encyclopedia of Mass Media and Society. California, CA: Sage.

Thompson, E. E., \& Yeboah, A. A. (2013). Health information from elite to popular media: Is 
Ghanaian media creating more space for health information/communication? Critical Arts: South-North Cultural and Media Studies, 2(3)7, 370-385.

Vasterman, P., Yzermans, C. J., \& Dirkzwager, A. J. E. (2005). The role of the media and media hypes in the aftermath of disasters. Epidemiologic Reviews, 27(1), 107-114.

Viswanath, K., Blake, K. D., Meissner, H. I., Saiontz, N. G., Mull, C., Freeman, C. S., ... Croyle, R. T. (2008). Occupational practices and the making of health news: A national survey of U.S. health and medical science journalists. Journal of Health Communication, 13(8), 759-777. /doi.org/10.1080/10810730802487430

World Health Organization. (2016, January). Ebola situation report. Retrieved from http://apps.who.int/ebola/current-situation/ebola-situation-report-6-january-2016

Yeboah-Banin, A. A., \& Amoakohene, M. I. (2017). The Dark Side of Multi-Platform Advertising in an Emerging Economy Context. Multi-Platform Advertising Strategies in the Global Marketplace, 3053. 


\section{LIST OF TABLES}

Table 1. Procedure for data analysis and interpretation

Steps

Step 2: Initial coding (Etic codes)

Step 3: Combining initial codes to create emic codes

Step 4: Theme development

\section{Examples}

RQ1- Initial labels include not enough health news, learning on the job, health stories not done, journalists not trained in health reporting, we are doing our best,

RQ 2- initial codes include: skeptical of government, the Ghanaian lifestyle, mistrust of government, editorial decision, use the internet, vox pop,

RQ 3- Initial codes include: signs and symptoms, blood oozing from the nose, handwashing, use hand sanitizer, government delegations, training sessions, government preventive measures, internet and social media,

RQ 4- Initial codes: include fear and panic, reechoing the society,

RQ 1- Low knowledge of health reporting, Unspecialized journalists, journalism work practices

RQ2- Social and organizational influences Personal experiences Dependence on internet Strategies for accessing information

RQ 3 - Preventive information Government responsibility Management of cases

- Under-developed health journalism

- Official sourcing, alternative sourcing or Flushing out

- Editorial constraints, journalism of conversations, or journalism of advocacy/mediation

- Causing or reflecting fear 
Table 2: Respondent's demographic information

\begin{tabular}{cc}
\hline CHARACTERISTIC & $(\boldsymbol{n})$ \\
\hline Ownership & 5 \\
Public & 13 \\
Private & \\
Gender & 9 \\
Male & 9 \\
Female & \\
& \\
Journalism Experience (years) & 4 \\
$1-5$ & 8 \\
6-10 & 6 \\
$11-20$ & \\
Position & 7 \\
Journalists/reporters & 5 \\
Senior journalists/reporters & 6 \\
Producers/Editor & \\
Education level & 6 \\
Bachelor's degree & 5 \\
Higher National Diploma (HND) & 3 \\
Paster's degree & 4
\end{tabular}

